\title{
Developing and Establishing Statistical Indicators for Fostering the Quality of Omani HEIs
}

\author{
Z. A. Al-Hemyari, A. M. Al-Sarmi \\ Ministry of Higher Education, P. O. Box 82, P. C. 112, Oman
}

\begin{abstract}
The theme of assessing the quality of HEIs has received a considerable attention from different international organizations such as the UNESCO, World Bank, OECD, EUA, HEFCE, and CHESASSE as well as from world leading HEIs. The quality of "input", "output" and "processes" of HEIs are widely examined by the use of statistical indicators (SIs) technique. In addition, SIs are one of the robust indices and represent a key methodology to assess the quality and quality improvements of HEIs.

The present article is set to service the following objectives [to]: explain the goals and objectives of HEIs; discuss the concepts, purposes and difficulties of statistical indicators; assess the "internal consistency of the measure"; study the "validity"; "reliability" and finally to explore the "feasibility" of the indicators selected.

In order to assess the features of SIs, a survey in the form of a questionnaire has been conducted. It has been distributed to 77 members of academic staff of HEIs in Oman.

Numerical computations of alpha reliability and split-half reliability show that the "internal consistency of the scale" is very good. The results of the analysis of the survey show that the measures of "validity", "reliability" and "feasibility" have a considerable gain. Findings, conclusions and recommendations are then reported.
\end{abstract}

\section{Introduction}

Indeed, "the use of statistics has permeated almost every facet of our lives" ([19]). In addition, statistical theory and methods as well as the use of statistical applications and analyses have affected practically and substantially of all disciplines including physics, biology, chemistry, agriculture, engineering, economics, business, education, sociology, psychology and others.

The application of statistics in social sciences, especially in the field of education, have increased virtually. Instead of calculating the percentages, means and standard deviations as it was in the past, especially in the field of education, have increased virtually. Instead of calculating the percentages, means and standard deviations as it was in the past, the application of advanced and elegant procedures such as estimating, testing, designing experiments, data mining and model building in the present have been widely used.

Qualitative and quantitative statistical indicators (SIs)/performance indicators (PIs) represent a very popular topic and a sophisticated application of statistics in education. SIs are keys and robust procedures in assessing the continuous advancement of institutional performance. In this context, reinforcing the quality of teaching and learning of HEI during statistical indicators application and benchmarking has become critical in many countries (Al-Hemyari and Al Sarmi [1, 2, and 3]).

Moreover, the concept of statistical indicators is an effective theme in operations management and has recently gained a very consideration due to its relation to quality audit of HEIs. Many literature sources have elaborated on the development and implementation of SIs in different areas of operations management/quality management in recent years. In addition, SIs represent the keys and robust procedures to assess the continued advancement of institutional performance. In this context, they become a critical factor to reinforce the quality of teaching and learning of HEIs ([1] and [2]).

Actually, the uses of SIs in HEIs have many advantages in controlling the variations of learning and teaching activities and in improving the quality and system outputs. They can be used for many purposes in HEIs.

HEIs have to exploit the benefits of SIs and then reflect them on the advancement of the institutional "input", "process" and "output". In order to apply the above advantages, HEIs are required to refine and describe their own "goals", "objectives", and "strategies" based on their institutional "mission", "vision" and "core values". Then, they have to develop some indicators to monitor their "inputs", "processes", "programs", "outputs", performance, and to compute the positions they hold in the higher education sector.

In addition, HEIs in the "developing countries" suffer two serious problems: the first one is the 
"transparency", which is not fully spread and the second problem is related to the weakness of "accountability". In order to ensure the "transparency" and strengthen the "accountability" in HEIs, HEIs in "developing countries" should be assiduous; more interested in the issues of developing and applying some SIs, and disseminate the outcomes in relation to their performance to the society and stakeholders.

There are many serious reasons that certainly raise a doubt about the method of refining the indicators and the efficiency of the indicators as reliable tools to measure the performance of activities/institutions. Thus, feasibility, reliability and validity of the proposed indicators are an important topic to study.

The composition of this research is as follows: the literature is reviewed in Section 2. The research aims are explained in Section 3 and the proposed goals and objectives are given in Section 4. Sections 5-7 discuss the concepts, purposes and difficulties of statistical indicators respectively. Some proposed SIs are given in Section 8. In Section 9, the methodology of studying the feasibility, reliability, and validity is presented. In Section 10, the population, sample and data collection from the respondents are clarified. In Sections 11 and 12 the characteristics of SIs (measures of internal consistency, feasibility, validity and reliability) the findings, numerical results and recommendations are given. Section 13 summarizes the conclusions.

\section{Literature Review}

The research has been conducted on the statistical indicators to study and estimate the performance of HEIs in developed and developing countries, international bodies and institutions. In addition, there are many papers, which have been produced in relation to some desirable attributes and properties of SIs.

In the last few decades, quality of HEIs, through the attention given by many international organizations like "United Nations", "Scientific and Cultural Organization (UNESCO)", "World Bank", "Organization of Economic Co-operation and Development (OECD)", has become one of the most important issues of HEIs. It has turned into the most popular issue in the society "whether public or private HEIs are meeting their goals and objectives which are declared in their mission and vision or not" ([1] and [2]). Then, the national/international affirmation/attention of studying this problem has produced many papers and journals related to the performance of HEIs have been produced and investigated the problem of constructing the SIs.

The background of this research is related to the needs of the Ministry of Higher Education in Oman: constructing SIs in order to monitor rendering, fulfillment and accomplishment of the missions, strategic plans, goals and objectives of HEIs and to better understand the obstacles that weaken their performance.

Kaufman [17], for example, has published the first paper of our interest, which coined the concept of performance measures/indicators.

Barneston and Cutright [5] have proposed and applied some SIs in Alberta College, Canada. Yackulic and Noonan [16] have studied the performance of teacher training strategy in Canada using 34 quality indicators.

Many other applications of SIs can be found in [1], [2], [6], [8], [10] and [18].

Furthermore, different scholars and authors have studied the properties of SIs. The first author in this direction was Cronbach [14]. He is the first who has studied the concept of the reliability of psychological and educational measurements. In addition, Cronbach [15] was able to fit the practical reliability to the general conditions and theory.

Franceschini et al. ([11] \& [12]) have studied some other general and special properties like exhaustiveness, non-redundancy, monotony, consistency and uniqueness of SIs.

In a project for the European HEIs, Kaiser and Vught [13] have proposed the "conceptual, empirical and methodological framework relevant for the development" of the European HEIs, which included 14 dimensions and 32 indicators. The paper was designed to assess "the relevance of the dimensions selected", and "the quality of the indicators selected", and to supply "data that would allow further analyses of the dimensions, their clustering, the indicators, their potentials and pitfalls".

It may be noteworthy to mention that Kaiser and Vught [13] and Vught and Ziegele [20] have studied the attributes of "validity" and "feasibility" by partitioning each measure to five and four factors respectively. Numerous references (e.g. [13-15], [23], [18] and [19]) have explained some of the attributes/properties of SIs.

\section{Aims of this Research}

As mentioned earlier, Al-Sarmi and Al-Hemyari ([1], [2], and [3]) proposed goals and objectives for HEIs in Oman and studied extensively the characteristics of the proposed goals and objectives on the bases of some general, internal and substantial properties.

In order to study and appraise the accomplishments of HEIs and the level of achieving the "goals" and "objectives" of HEIs in Oman, the HEIs have to collect and report data for every indicator, which assumed significance to appraise the accomplishments and the current situation of HEIs. It is apparent that "for these indicators it might be that the data reported depend on the person or department that reports the data" ([20]). 
To find out whether the "reliability/validity/ feasibility" problem is perceived to exist by the responding HEIs, the HEIs have been asked to evaluate the indicators through the expressions: "indicator A is a valid indicator for this dimension", "the information is reliable", "the process of collecting and reporting the data is feasible", ([13] page 78, and [20] pages 19-20).

As explained in sections 1 and 2, the process of implementing the SIs in HEIs to monitor their performance is dependent on many serious factors, which affect the success of the implementation of SIs and seizing sound information from SIs. In fact, in the literature of SIs those factors are converted/modeled as properties or features of PIs like validity, reliability and feasibility.

Thus, the article is planned to service its fundamental aims [to]: explain the goals and objectives of HEIs, discuss the concepts, purposes and difficulties of statistical indicators, assess the internal consistency of the measure (i.e. Cronbach's alpha and split-half reliability), study the validity, clarify the reliability/trustworthy, and explore the feasibility of the indicators selected.

\section{Goals and Objectives}

In order to study and appraise the accomplishments, output and activities of HEIs in any country, the "institution's mission, broad and consistent goals of HEIs should be clearly defined and refined to measurable, brief and clear objectives that reflect the broader goals" ([1-2]). Then, the SIs should be identified, selected and aligned with the objectives of HEIs ([2, 3]).

It may be necessary to provide in this section, the definitions of "mission statement", "goals" and "objectives", as given below:

Definition 1: "A Mission Statement is a general, concise statement outlining the purpose guiding the practices of an institution or school/college" (see [1]).

Definition 2: "Goals are broad, general statements of what the program, course, or activity intends to accomplish" (ibid).

Definition 3: "Objectives are brief and clear statements that describe the desired learning outcomes of instruction; i.e., the specific skills, values, and attitudes students should exhibit that reflect the broader goals" (ibid).

The relationship between goals, objectives, strategies (ST) and the statistical indicators (SIs) can be shown by the Figure 1 .

This project has been conducted for the Ministry of Higher Education, Oman to appraise the accomplishments of HEIs and the level of achieving the "goals" and "objectives" of HEIs in Oman ([1], [2]). The following five areas of the research have been proposed: (1) "access and admission in HEIs",
(2) "academic excellence in teaching/learning", (3) "excellence in research", (4) "internationalization", and (5) "community engagement".

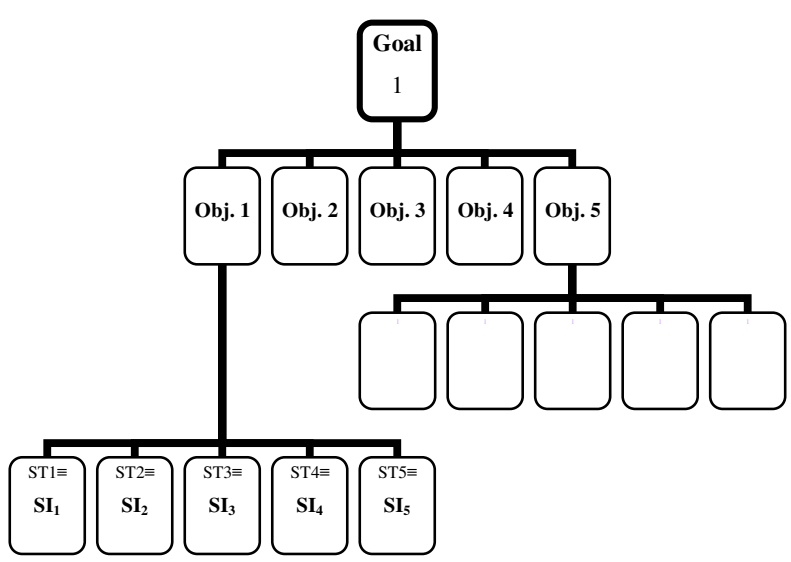

Figure 1: The relation between goals, objectives and indicators

The above areas are refined to the following objectives:

1.1 “ To increase students' enrolment rate; 1.2 "To increase students' progression and retention rates"; 1.3 " To decrease expenditure and cost per student"; 1.4 To upgrade financial resources; 1.5 " To enhance employment rate of graduates" and 1.6 "To ensure social equity".

2.1 "To enrich academic programs; 2.2 "To clarify institutional strategies"; 2.3 "To enhance learning and teaching"; 2.4 To emphasize on scientific and technical studies; 2.5 "To ensure student outcomes at high standard"; 2.6 "To improve learning capability of students"; 2.7 "To improve performance of executive management"; 2.8 "To improve performance of academic staff"; 2.9 "To improve performance of non-teaching staff"; 2.10 "To upgrade postgraduate programs"; 2.11 "To increase the use of information and communication technologies in teaching, learning and training" and 2.12 "To improve institutional infrastructure".

3.1 "To strengthen research capability and performance" and 3.2 "To improve research activities and outcomes". 4.1 "To develop collaborative/ international student exchange programs; 4.2“To enhance external assessment for academic programs and professional exams"; 4.3 "To increase funds for internationalization". 4.4 "To enhance collaborative international professional activities and events" and 4.5 "To increase international student internships".

5.1 "To increase graduates rate"; 5.2 "To participate in community activities"; 5.3 "To increase percentage of Omani academic and non-academic staff" and 5.4 "To direct the research to the community needs and issues". 
Remark 1: The number of each objective is consisted of two numbers, where the first one stands for the goal and the second specifies the sequence of objectives.

Remark 2: Indeed, proposing the goals, objectives and SIs for performing HEIs has to be followed by a necessary process of evaluating and testing the proposed goals and objectives. For the purpose of testing and evaluating the properties/characteristics of goals and objectives, the judgment criteria of the package (goals and objectives) are proposed and studied in [1], [2].

\section{Statistical Indicators}

The definition of statistical indicator is not unified and it depends on the uses and purposes of the international bodies. The following are two famous definitions of statistical indicator.

Definition 4: A statistical indicator is "A data element that represents statistical data for a specified time, place, and other characteristics, and is corrected for at least one dimension (usually size) to allow for meaningful comparisons" (see [9]).

Definition 5: "Statistical indicators are any quantitative data that provide evidence about the quality or standard of higher education" (see [4]).

It may be worth to mention that the statistical indicators as per the above definitions are data collected regarding higher educational activities with some characteristics, and they may be used for many educational purposes.

Statistical indicators have many advantages and benefits from which HEIs can perform their activities and benchmark the obtained performances in order to compare their performances with similar HEIs and to inform the public about the comparative results between these institutions.

\section{The Purposes of SIs}

According to [1-3]; [5]; [10]; [16]; [17] and [18], below are some of the purposes of PIs:

- "To provide reliable information to the stakeholders on the nature and performance of the higher education institutions".

•"To allow comparisons between individual universities/colleges of a similar nature".

•"To enable universities'/colleges' benchmark their own performance".

-"To inform the Government on the policy developments in higher education, marketing, and manpower planning".
- "To contribute to the public the accountability of higher education sector".

- "To enable universities/colleges provide the internal management".

- "To provide the student with a choice of an Institution and flexibility in entry and education type (full time/part time)".

- "To inform the industry, technology and research councils of how to distribute the research funds".

-"To stimulate competition within and between institutions".

- "To facilitate international comparisons".

•"To improve the quality of higher education provision".

• "To allow ranking of HEIs".

\section{Practical Problems in Designing Statistical Indicators}

Some of the common practical remarks and problems on construction of performance indicators (ibid) are given below:

- "The first practical problem on the construction the SIs is exemplified in the "availability", "validity" and "reliability" of "raw statistical data", and the "feasibility" of getting new "raw statistical data" if they are not available.

-The second problem is related to the mechanisms of sampling, collecting, gathering and analysis the data, i.e., the diminution of the representation of the population and uniformity in the way of collecting the data from a HEI to another HEI and in the way of collecting the data from one period to another within the same HEI.

-Another difficulty is related to the way of constructing the SIs, i.e., there is no global (comprehensive) statistical indicator of the "added value" of an institution activity. The common approach in most of the HEIs of the world is proposing a set of "ad hoc" indicators (based on experimental and empirical background of the author (s)) for each institution activity. In most cases, each institution is using different set of indicators.

-HEIs must know what they want to measure before using any available SIs or to follow any common practice of SIs. They have to be refined a set of nationally and internationality "goals", "objectives" and to align suitable and efficient procedures to achieve these "objectives".

-For the useful use of the SIs and for easy and clear conclusions, in addition to HEIs clear knowledge of what should be assessed and what are their "goals", "objectives" and SIs, it is necessary to understand what the SI is required to measure and how the values of one activity may be co-related or dependent to the values of other activity. This problem may convey that the corresponding SIs may be co-related or dependent and in this case, one 
should be very careful when he/she wants to discuss the related results.

-One of the common problems associated with statistical indicators is related to setting targets of SIs for future period without considering uncertainty conditions. Over the time, we may find that our targets are not possible to meet because uncertainty conditions have not been considered.

\section{Grouping Statistical Indicators}

Several authors/researchers have studied the problem of appraising the accomplishments of HEIs and the level of achieving the "goals" and "objectives" of HEIs and the problem of constructing the statistical indicators in different countries and institutions. It may be noted that Ewell [8] has proposed eight performance indicators for the Education Commission of the United States. In a study that was conducted for the Center for Organizational Development and Leadership, Rutgers University (Ruben [6]), the five indicators area were "teaching/learning, scholarship /research, services/outreach, workplace satisfaction, and financial". Yackulic and Noonan [16] have referred to 34 quality indicators for teacher training in Canada.

Considering the difficulty and diversity of Oman higher education institutions, i.e. it is usually inaccurate to consider a single indicator for each activity; it has become necessary to combine/ consider and align many SIs as a group of indicators, each of which is able of reflecting/responding to one activity or one part of one objective. In addition, each field of indicators (indicators of many groups/objectives) should reflect one particular educational objective/goal. In turn, each goal should have a reasonable number of related objectives and SIs.

In this section, the educational objectives are refined into 150 quantitative and qualitative indicators that are assumed to be critical to HEIs in the Sultanate of Oman. The SIs are related to students, undergraduate studies, graduate studies, research, faculty members, non-academic staff, cooperative education, resources, satisfaction, engagement, grants, extra-curriculum activities, internationalization, community and resources. They conferred the urgent need for improvement, globalization and re-directed the resources and remodeled the system output of HEIs to meet the market requirements.

The above areas are refined into 29 objectives and 150 qualitative and quantitative indicators denoting the indicators by $S I_{i j k}$ (where the indicator symbols ijk stand for the "goal", "objective" and the indicator respectively). Some of the proposed indicators are as follows:

111 "The total number of recent General Diploma graduates registering in the program/ department

/institution".

112 "The total number of students enrolled in program/ department /institution (full time)".

113 "The total number of students enrolled in program/ department /institution (part time)".

114 "The percentage of Omani students in comparison with the total number of "General

Diploma graduates".

115 "The total number of postgraduates (M. Sc. and Ph.D.)".

116 "The total number of internal scholarships from government organizations".

117 "The total number of internal scholarships from non-government organizations".

121 "Progression rate".

122 "Retention/attrition rate".

123 "Resumption rate".

131 "Academic staff expenditures as a percentage of total expenditures".

132 "The ratio of expenditure per year in relation to total number of students".

133 "The ratio of expenditure per year in relation to total successful students".

134 "The annual average fees charged by the institution for each degree and specialization".

141 "The percentage of government contribution to each higher education institution".

142 "The amount of non-government contributions to institution.

143 "The ratio of income from consultancies in relation to total budget".

144 "The ratio of income from research in relation to total budget".

151 "Employment rate of graduates".

152 "The percentage of students' participation in national internships".

153 "The percentage of students' participation in "career guidance programs".

161 "The total number of recent General Diploma graduates registering in the program/department /institution (by gender)".

162 "The total number of students enrolled in the program/ department/institution (full time and by gender)".

163 "The total number of students enrolled in the program / department/institutions (part time and by gender)".

164 "Employment rate of graduates (by gender)".

211 "The total number of curriculum development and revisions (for each batch)".

212 "The total number of current undergraduate programs".

213 "The total number of current postgraduate programs". 
214 "The total number of programs accredited by professional (national or international) bodies".

215 "The ratio of program elective hours to total number of hours".

216 "The ratio of courses taught in foreign languages in relation to the total number of courses offered". 217 "The ratio of credit points of foreign language courses (other than English) in relation to the total number of credit points (compulsory or optional)". 221 "Communicating vision and mission of the institution to academic staff".

222 "Communicating vision and mission of the college to academic staff".

223 "Communicating goals and objectives of the college to academic staff".

224 "Communicating core values, strengths, weakness, threats and opportunities of the department to academic staff'.

231 "The Average of class size for undergraduate students (program/institution)".

232"Advisor's performance".

233 "Student capability".

234 "Teaching methods".

235 "Assessment strategies".

236 "Interaction among students".

237 "Quality of the coursework".

238 "Student-instructor interaction".

239 "Student-Instructor ratio for undergraduate students".

2310 "The ratio of approved and settled student appeals".

2311 "The ratio of computers in relation to all students".

\section{Research Framework and Design}

As mentioned earlier, the final selection of proposed SIs should be performed on the bases of many decision criteria. In this paper, we will study three of them, i.e. reliability, validity and feasibility. The methodology of testing the level of each criterion/property is based on a survey method, which has been utilized for the data acquisition of this research from the target population.

It is well known that the validity of the scale is one of the important steps of a survey designing. In order to assure the validity of the scale used, the modified research instrument, which is based on an instrument and which is proposed in [13], has been modified and used. The questionnaire in this research is based on "five-level Likert items scale" (Strongly Disagree (1); Disagree (2); Cannot Say (3); Agree (4); Strongly Agree (5)). It performs as a prime function and it is considered as one of the main steps of judging the statistical indicators.

It is noticed that there are few papers, which focused on studying and applying the decision criteria of statistical indicators; whereas most of the used indicators were based on ad hoc bases. Due to the similarity of interest and purpose of testing the proposed indicators with the indicators of [13], it seems reasonable to proceed on the same manner as in [20] and [13]. This is to say we need to determine whether "the indicators measure what they claim to measure", "the measurement of the indicator shall be the same regardless of who collects the data or when the measure is repeated" and to study the "data quality that are available or can be collected with an acceptable level of effort".

The questionnaire in this research was designed to serve the following purposes: assessing the internal consistency of the measure and assessing the properties of the indicators. This action was performed through the following questions respectively: i) what is the "validity" level of the $S I_{i j k}$ in assessing the performance of HEIs? ii) what is the "reliability" level of the information provided by the $S I_{i j k}$ ? and iii) what is the "feasibility" level of the process of collecting data on the $S I_{i j k}$ ?

In fact, the feasibility of the process of collecting data on indicators is a complex concept and it depends on many factors. For the problem of assessing the feasibility of the proposed indicators, the measure of feasibility is separated into three factors. The factors are:

a. The process of collecting data on the indicator $S I_{i j k}$ (Scale: 1= Very complicated, 2= Complicated, 3= Cannot Say, 4= Simple, 5=Very simple), b. The time needed for collecting data on the indicator $S I_{i j k}$ (Scale: $1=$ Very much, $2=$ Much, $3=$ Cannot Say, $4=$ Little, 5=Very little), and c. The availability of databases on the indicator $S I_{i j k}$ (Scale: 1= Not available, 2= Cannot Say, 3= Slightly available, 4= Partially available, $5=$ Available) .

\section{Population and Sample}

The population of this research includes all academic staff members of the 31 public and private HEIs. The sample size for this research is 77 senior academic staff drawn from the population, which is about $5.5 \%$ of the available academic staff of private HEIs. Table 1 shows that the questionnaires are distributed randomly to the senior Ph.D. holders of academic staff in 31 HEIs.

Table 1: The distributed (D) and received (R) questionnaires from HEIs

\begin{tabular}{|l|l|l|l|}
\hline \hline & \multicolumn{1}{|c|}{ HEIs } & D & R \\
\hline \hline 1 & Sultan Qaboos University & 10 & 9 \\
\hline 2 & College of App. Sciences-Ibri & 2 & 2 \\
\hline
\end{tabular}




\begin{tabular}{|l|l|l|l|}
\hline 3 & College App. Sciences - Rustaq & 2 & 2 \\
\hline 4 & College App. Sciences - Sohar & 3 & 3 \\
\hline 5 & College App. Sciences - Nizwa & 2 & 2 \\
\hline 6 & Sohar University & 4 & 4 \\
\hline 7 & University of Nizwa & 10 & 8 \\
\hline 8 & Dhofar University & 2 & 2 \\
\hline 9 & German Univ. of Tech. in Oman & 2 & 0 \\
\hline 10 & Arab Open Univ. Oman & 1 & 0 \\
\hline 11 & A'Sharqiyah University & 1 & 1 \\
\hline 12 & Caledonian College of Eng. & 4 & 4 \\
\hline 13 & College of Mazoon & 3 & 3 \\
\hline 14 & Middle East College of Inf. Tech. & 3 & 3 \\
\hline 15 & Int. College of Eng. \&Management & 1 & 0 \\
\hline 16 & Modern College of Business \&Sci. & 3 & 3 \\
\hline 17 & Inter. Maritime College of Oman & 2 & 2 \\
\hline 18 & Gulf College & 2 & 2 \\
\hline 19 & SUR University College & 2 & 1 \\
\hline 20 & Al-Buraimi Univ. College & 1 & 1 \\
\hline 21 & Majan Univ. College & 1 & 1 \\
\hline 22 & Oman Tourism College & 3 & 3 \\
\hline 23 & Scientific C. of Design & 1 & 0 \\
\hline 24 & Bayan College & 1 & 0 \\
\hline 25 & Oman Medical College & 1 & 1 \\
\hline 26 & College of Banking \&Fina. Studies & 2 & 2 \\
\hline 27 & Waljat College of App. Sciences & 2 & 2 \\
\hline 28 & Al-Zahra College for Woman & 2 & 2 \\
\hline 29 & Oman College of Manag. \& Tech. & 2 & 1 \\
\hline 30 & Muscat College & 1 & 0 \\
\hline 31 & Oman Dental College & 1 & 0 \\
\hline & Total & 77 & 64 \\
\hline
\end{tabular}

In this sample, academic staff of HEIs have been requested to judge the expressions (i, ii, iii) given in the last section. In order to get sound data from the academic staff and high percentage of completed and received questionnaires, the academic staff of HEIs have been adequately informed of the aims, steps, methodology, implementation and data collection of the project. In addition, the academic staff of HEIs were given enough time to complete the questionnaires.

Table 1 shows that 64 completed surveys out of 77 distributed surveys.

\section{Measures of Internal Consistency}

It is well known that the "reliability" measures are very useful measures in applied sciences including psychology and education. At the same time, there are many usages of "reliability" concepts, when the "reliability" measures are not unified. Each measure has a different formula to estimate and different usage. They are "Inter-rater", "Test-retest", "Parallel-forms", and "Internal consistency". The measures of internal consistency have been proposed in [14], which are the most important measures to test the accuracy of questionnaires. After that, different researchers have followed and applied Cronbach measures in social, applied sciences, especially in psychology and education. In this paper, we estimate and discuss the measures of internal consistency, i.e. Cronbach's Alpha and Splithalf reliability.

\subsection{Cronbach's Alpha}

In order to investigate the stability of a scale and to study the accuracy of questionnaire, it has been determined that the measure of Cronbach's alpha can effectively respond to the mentioned tests and can provide valuable information about the survey as well as information about the stability of the scales of measurement. In addition, it is determined that Cronbach's alpha can refer to the quantity of random error associates with the measurements, where "the accuracy of the measurements is important, whether for scientific or practical purposes, the investigator should evaluate how much random error affects the measurements" (see Cronbach [14]).

The respondents' results have been used to estimate the measures of internal consistency; whereas the analysis of respondents' results has been performed by SPSS (IBM Version-20).

The estimated value of Cronbach's alpha from the collected data equals to 0.891 . This result shows that the internal consistency of the scale is very good.

\subsection{Split-half Reliability}

The second important measure of internal consistency, the Split-half reliability, is be studied and calculated in this section of the questionnaire. Split-half reliability indicates the correlation between scores of first half (part) and second half (part) of the items of the scale" (ibid). It may be worth mentioning here that the total items put in the test is randomly divided into two parts.

The estimated value of Guttman Split-Half Coefficient between first half (75 indicators) and second half (the remaining 75 indicators) of the scale equals 0.832 , indicating that the scale of the questionnaire have a very good reliability.

\section{Validity, Feasibility and Reliability}

\subsection{Concepts}

Briefly speaking, the problem of studying and appraising the accomplishments, output and activities of HEIs were followed by a process of refining the "goals" in the first stage and proposing "objectives" of the HEIs in the second stage and developing educational qualitative and quantitative statistical indicators in the third stage. Finally, 
proposing the decision criteria of the statistical indicators and evaluating and testing the indicators in the fourth stage of the framework of the statistical indicators project of HEIs in Oman.

It is worthy to mention here that the general decision criterion regarding the properties of SIs are different from that of "goals" and "objectives" (see e.g. [3]). They are given below:

c1."Assessing the relevance between the proposed indicators and objectives",

c2. "Assessing how much random error affects the measurement of the indicators?"

c3. "Assessing the clarity of the proposed indicators to the respondents of HEIs",

c4. "Assessing the statement: Indicator is a valid indicator to assess the performance of HEIs",

c5. "Assessing the statement: The information provided by the indicator is reliable to assess the performance of HEIs",

c6. "Assessing the statement: The process of collecting data on the indicator is feasible".

In this paper, it is planned to study the "validity", "feasibility" and "reliability" of the 150 indicators. Some of them are given in section 3. Validating of the indicators is a very important step and it assures that they are significant and accurate tools to study and appraise the accomplishments, output and activities of HEIs. The values of "validity", "feasibility" and "reliability" are estimated based on the respondents' opinion of the questionnaire.

In this section, the definition of the terms of "validity", "feasibility" and "reliability" are given below (see, [20]):

Definition 6 Validity: "the indicator measures what it claims to measure and is not confounded by other factors".

Definition 7 Reliability: "the measurement of the indicator is the same regardless of who collects the data or when the measure is repeated. The data sources and the data to build the indicator are reliable", i.e. the information gained by indicators is sound, solid and trustworthy.

Definition 8 Feasibility: "the required data to construct the indicator is either available in the existing databases and/or in the higher education and research institutions, or they can be collected within acceptable effort".

\subsection{Results}

It is widely known that the best way to compare the behavior and the properties of SIs is by using the theoretical calculations based on the possibility to derive explicit expressions of the properties. Due to non-existence of explicitly mathematical expressions of "reliability", "validity" and "feasibility", we are left with no other choice than an opinion/survey study.
In order to observe the performance of the proposed indicators and to compare between them, we have calculated the average of the components/factors mentioned of each criterion. For space limitation, results of "reliability", "validity" and "feasibility" of 40 indicators are given in Tables 2, 3 and 4 . The following observations are based on the numerical results of this paper:

i. Table 2, shows that the computed values of "reliability" $(R)$ of most of the indicators, except one (0.67), are good and they ranged from 0.82 to 0.97 , i.e., most of the indicators give acceptable and reasonable values of" reliability" on the bases of the opinions of the respondents.

ii. Table 3, shows that the computed values of "validity" of indicators 111 to 223, except one indicator (0.64), are good and they ranged from 0.81 to 0.97 , i.e., all the given indicators give acceptable and reasonable values of "validity" on the bases of the opinions of the respondents

iii. Table 4, shows that the computed values of "feasibility" (F) of the given indicators, are good and they ranged from 0.83 to 0.97 , i.e., all given indicators give acceptable and reasonable values of feasibility on the bases of the opinions of the respondents.

iv. In general, the computations of "reliability", "validity" and "feasibility" of the most suggested indicators, except eight of them, are good.

v. As expected, the following indicators have low "feasibility/reliability/validity" $(\approx 0.6)$ because of the lack of data bases of indicators: "The ratio of approved and settled student appeals", "The total number of ISI highly cited researchers in relation to all academic staff", "The Growth Index of research quality" and "The Growth Index of research performance".

vi. As expected, the worst indicators are the indicators that are related to the research citation and research performance in the sense of least computed values of "feasibility/reliability/validity" and they constitute a major problem in HEIs because of the national and international databases for those indicators that are not accessible in HEIs. For to this reason, the "feasibility" and "reliability" of these indicators are not measured and they are expected to be much lower than all other indicators. In addition, the indicators regarding expenditures on research or the amount of research funding form HEIs or national research bodies show very low ratios and indicate that few of HEIs have engaged with such activities.

vii. The following indicators: "Employment rate of graduates", "Employment rate of graduates (by gender)", also have low acceptable values of the validity, feasibility and reliability of indicators $(\approx 0.61$ to 0.69$)$ in comparison with the other indicators because many private HEIs have not collected data continually on graduate employment. 
viii. It has been noticed that all the other quantitative indicators have good values of "reliability", "validity" and "feasibility" (i.e. from .80 to .95) and are greater than those indicators given in ii and iii above.

ix. Generally speaking, most of "feasible/ reliable/valid" indicators are based on students and academic staff's surveys (221- 224, 232-238, 252$259,264,265,271-275,288-2810,2113,21211$, i.e. all qualitative indicators are better than the quantitative indicators in terms of higher values of "validity, feasibility and reliability" (from .93 to .97).

\section{Table 2: Values of Reliability}

\begin{tabular}{|c|l|l|l|l|l|l|l|}
\hline ijk & $R$ & ijk & $R$ & ijk & $R$ & ijk & $R$ \\
\hline 111 & 0.82 & 131 & 0.91 & 211 & 0.93 & 224 & 0.93 \\
\hline 112 & 0.81 & 132 & 0.91 & 212 & 0.94 & 231 & 0.93 \\
\hline 113 & 0.83 & 133 & 0.82 & 213 & 0.92 & 232 & 0.94 \\
\hline 114 & 0.84 & 134 & 0.83 & 214 & 0.94 & 233 & 0.95 \\
\hline 115 & 0.86 & 141 & 0.93 & 215 & 0.94 & 234 & 0.97 \\
\hline 116 & 0.90 & 142 & 0.93 & 216 & 0.92 & 235 & 0.96 \\
\hline 117 & 0.89 & 143 & 0.85 & 217 & 0.84 & 236 & 0.95 \\
\hline 121 & 0.91 & 144 & 0.84 & 221 & 0.94 & 237 & 0.96 \\
\hline 122 & 0.90 & 151 & 0.67 & 222 & 0.93 & 238 & 0.95 \\
\hline 123 & 0.88 & 152 & 0.92 & 223 & 0.93 & 239 & 0.95 \\
\hline
\end{tabular}

Table 3: Values of Validity

\begin{tabular}{|c|l|l|l|l|l|l|l|}
\hline ijk & $V$ & $i j k$ & $V$ & $i j k$ & $V$ & $i j k$ & $V$ \\
\hline 111 & 0.83 & 131 & 0.92 & 211 & 0.95 & 224 & 0.94 \\
\hline 112 & 0.81 & 132 & 0.92 & 212 & 0.95 & 231 & 0.92 \\
\hline 113 & 0.85 & 133 & 0.83 & 213 & 0.93 & 232 & 0.95 \\
\hline 114 & 0.85 & 134 & 0.84 & 214 & 0.95 & 233 & 0.94 \\
\hline 115 & 0.87 & 141 & 0.95 & 215 & 0.95 & 234 & 0.96 \\
\hline 116 & 0.87 & 142 & 0.92 & 216 & 0.93 & 235 & 0.95 \\
\hline 117 & 0.91 & 143 & 0.84 & 217 & 0.85 & 236 & 0.96 \\
\hline 121 & 0.92 & 144 & 0.83 & 221 & 0.91 & 237 & 0.97 \\
\hline 122 & 0.92 & 151 & 0.69 & 222 & 0.92 & 238 & 0.96 \\
\hline 123 & 0.85 & 152 & 0.93 & 223 & 0.94 & 239 & 0.94 \\
\hline
\end{tabular}

Table 4: Values of Feasibility

\begin{tabular}{|c|l|l|l|l|l|l|l|}
\hline ijk & $F$ & $i j k$ & $F$ & $i j k$ & $F$ & $i j k$ & $F$ \\
\hline 111 & 0.93 & 131 & 0.91 & 211 & 0.91 & 224 & 0.91 \\
\hline 112 & 0.92 & 132 & 0.91 & 212 & 0.94 & 231 & 0.90 \\
\hline 113 & 0.94 & 133 & 0.81 & 213 & 0.92 & 232 & 0.91 \\
\hline 114 & 0.92 & 134 & 0.82 & 214 & 0.92 & 233 & 0.90 \\
\hline 115 & 0.94 & 141 & 0.90 & 215 & 0.89 & 234 & 0.91 \\
\hline 116 & 0.93 & 142 & 0.91 & 216 & 0.92 & 235 & 0.92 \\
\hline 117 & 0.95 & 143 & 0.90 & 217 & 0.83 & 236 & 0.91 \\
\hline 121 & 0.92 & 144 & 0.84 & 221 & 0.90 & 237 & 0.92 \\
\hline 122 & 0.91 & 151 & 0.64 & 222 & 0.89 & 238 & 0.92 \\
\hline 123 & 0.87 & 152 & 0.91 & 223 & 0.92 & 239 & 0.95 \\
\hline
\end{tabular}

\section{Conclusion}

The problem of assessing the "reliability", "validity" and "feasibility" of the proposed SIs, as well as the internal consistency of the questionnaire, has been studied in this paper. The study of the above properties through the responses to the questionnaire shows that most of the proposed SIs have a considerable gain in the measures of "reliability", "validity" and "feasibility" while a few of the indicators need further verification. The study of the above properties through the responses to the questionnaire shows that the project is adequate in terms of characteristics of SIs, and thus it is suitable for the implementation at HEIs. Thereby, the use of the proposed indicators for studying and appraising the accomplishments, output and activities of HEIs in Oman is highly recommended.

\section{Acknowledgements:}

The authors appreciate the overwhelming support they received from the Ministry of Higher Education, Oman in conducting this project. The authors are grateful to Mr. Saad Hatem Hasan Al-Jibouri, College of Applied Science, Nizwa for proofreading the paper.

\section{References}

[1] A. M. Al-Sarmi, and Z. A. Al-Hemyari, "Goals and Objectives: Statistical techniques and measures for Performance Improvement of HEIs in Oman", Int. J. of Management in Education, Vol. 8, No. 3, 2014, pp. 244264.

[2] A. M. Al-Sarmi, and Z. A. Al-Hemyari, "Quantitative and Qualitative Indicators to assess the Quality of Teaching and Learning in Higher Education Institutions", Accepted in Int. J. of Information and Decision Sciences, Vol. 6, No. 4, 2014, pp. 369-392.

[3] A. M. Al-Sarmi, and Z. A. Al-Hemyari, "Some statistical characteristics of performance indicators for continued advancement of HEIs", Int. J. of Quality and Innovation, Vol.2, Nos.3/4, 2014, pp. 285-309.

[4] Analytic Quality Glossary

http://www.qualityresearchinternational.com/glossary/stati sticalindicators.htm (accessed 14 December 2014).

[5] B. Barnetson, and M. Cutright, "Performance indicators as conceptual technologies", Higher Education, 40, 2000, pp.277-292.

[6] B. D. Ruben (1999) Towards a Balanced Scorecard for Higher Education: Rethinking the College and University Excellence Indicators Framework, Center for Organizational Development and Leadership, Rutgers University, pp.1-10 [online] http://www.qci.rutgers.edu (accessed 19 June 2011).

[7] B. G. Heubeck, and J. T. Neill, "Internal validity and reliability of the 30 item Mental Health Inventory for Australian Adolescents", Psychological Reports, Vol. 87, 2000, pp.431-440. 
[8] D. Draper, and M. Gittoes, "Statistical analysis of performance indicators in UK higher education", Journal of Royal Statistical Society, A 167 (3), 2004, pp. 449474.

[9] European quality assurance in vocational education and training (EQAVET).

http://www.eqavet.eu/qa/gns/glossary/s/statisticalindicator.aspx(accessed 14 December 2014).

[10] P. Ewell (1994) 'Developing statewide performance indicators for higher education', in Ruppert, S.S. (Ed.): Charting Higher Education Accountability: A Sourcebook on State-Level Performance Indicators, Education Commission of States, Denver [online] http://onlinelibrary.wiley.com/doi/10.1002/he.3691995910 4/abstract (accessed 11 March 2013).

[11] F. Franceschini, M. Galetto, D. Maisano and L. Mastrogiacomo, "Properties of Performance Indicators in Operations Management: A Reference Framework", The International Journal of Productivity and Performance Management, Vol. 57, 2008, pp. 137-155.

[12] F. Franceschini, M. Galetto, and D. Maisano,

"Classification of Performance and Quality Indicators in Manufacturing", International Journal of Services and Operations Management, Vol. 2, No.3, 2006, pp. 294-311

[13] F. Kaiser, and F. van Vaught, In F. van Vaught Mapping the higher education Landscape: Towards a European Classification of Higher Education, 1st ed., Springer, Dordrecht: Netherlands, 2009.

[14] L. J. Cronbach, "My current thoughts on coefficient alpha and successor procedures", Educational and Psychological Measurement, 64 (3), 2004, pp.391-418.

[15] L. J. Cronbach "Coefficient alpha and the internal structure of tests", Psychomerika,16, 1951, pp.297-334.

[16] R. A. Yackulic, and B.W. Noonan, (2001) "Quality indicators for teacher training in Canada", Paper presented in the Proceedings of The 2001 Pan-Canadian Education Research Agenda Symposium. May 22-23, 2001, Lavel University Quebec City, Canada.

[17] R. Kaufman, "Preparing useful performance indicators", Training and Development Journal, 1988, pp.80-83.

[18]S.-H. Chen , Wang, H.-H. and K.-J. Yang, "Establishment and application of performance measure indicators for universities", The TQM Journal, 2009, pp.110 .

[19] S. M. Bird, "Performance indicators: good, bad, and ugly", Journal of Royal Statistical, Society , A 168(1), 2005, pp.1-27.

[20] Vaught, F. van and F. Ziegele, "Design and Testing the Feasibility of a Multidimensional Global University Ranking", CHERPA-Network, The Directorate General for Education and Culture, 2011, pp. 1-181. [online] http://ec.europa.eu/education/highereducation/doc/multiran k_en.pdf (accessed 4 January 2012). 